\title{
Antibiogram of Bacterial Isolates Obtained from Milk Samples in and Around Hyderabad, India
}

\author{
Shiva Jyothi ${ }^{1}$, Kalyani Putty ${ }^{1}$, R.N. Ramani Pushpa ${ }^{2}$, Hannan Umair ${ }^{1}$, Amol ${ }^{3}$, \\ Vijay Muley $^{3}$, K. Dhanalakshmi ${ }^{1}$ and Y. Narasimha Reddy ${ }^{1 *}$
}

${ }^{1}$ College of Veterinary Science, P. V. N. R. Telangana Veterinary University, Rajendrangar, Hyderabad-500030, Telangana, India

${ }^{2}$ NTR College of Veterinary science Gannavaram, India

${ }^{3}$ Zoetis, Mumbai, India

*Corresponding author

\section{A B S T R A C T}

\begin{tabular}{|l|}
\hline Key w o r d s \\
Bacterial isolates, \\
Mastitis, Antibiotic \\
sensitivity test, \\
Ceftiofur
\end{tabular}

\section{Introduction}

Mastitis has long been recognized as one of the economically important diseases affecting dairy cows and a major cause of economic loss to Indian dairy industry (Sasidhar et al., 2002). This condition is characterized by physical and chemical changes in the milk and pathological changes in the glandular tissue (Blood and Radostits, 1989). Overall losses due to mastitis in India were estimated to be Rs.7165.51 crores (Bansal and Gupta, 2009). Mastitis is also the most important reason for
The present study was undertaken to estimate the prevalence of bacterial pathogens in milk samples and to assess the antibiotic sensitivity pattern of the causative organisms in and around Hyderabad region of Telangana state, India. A total of 1143 milk samples were collected from cross bred dry cows from in and around Hyderabad region, and were subjected to bacteriological studies and in-vitro antibiotic sensitivity test. Out of 1143 samples, a total of 1168 bacterial isolates were obtained of which Staphylococcus sp. was found to be the most predominant followed by E. coli, Streptococci spp, and Pseudomonas spp. Antibiogram studies showed maximum sensitivity to ceftiofur with $60 \%$ for Staphylococcus sp. and Pseudomonas species, 58\% for Streptococcus sp. and $90 \%$ for E. coli that were isolated in the current study. Hence, the probable use of Ceftiofur as a potential antimicrobial (preferably for mastitis) in the tested geographic region was proposed from the findings of the current study.

culling of cows in the dairy industry (Barkema et al., 1999). The sub clinical form of mastitis in dairy cows is important because it is $15-40$ times more prevalent than the clinical form, reduces the milk production and adversely affects the milk quality (Seegers et al., 2003). Staphylococcus is the major etiological agent, followed by Streptococcus and E. coli causing subclinical mastitis in cows in India (Singh and Baxi, 1982). Since bacteria are the major etiological agents of mastitis, indiscriminate use of antibiotics without in vitro testing may lead to treatment failure and also results in 
development of resistance to antimicrobials. Identification of mastitis causing pathogens and identification of the antibiotic resistance pattern of the isolated bacteria are important prerequisites for implementation of effective treatment of mastitis. This information is needed not only to treat and control mastitis but also to address public health concerns (Dhakal et al., 2007). Rapidly-evolving Antimicrobial Resistance is a global concern to human health and food supply chain (Cosgrove and Carmeli, 2014). Hence the present study was conducted to isolate and identify the bacteria from milk samples and to study the antibiotic resistance pattern of isolates. To our knowledge, the present study is the first retrospective study that investigated the susceptibility patterns of pathogens isolated from dairy cows in India to Ceftiofur.

\section{Materials and Methods}

A total of 1143 milk samples were collected from crossbred dairy cows and processed for isolation of bacteria and their antibiogram was performed. Milk samples were centrifuged at $2000 \mathrm{~g}$ at $37^{\square} \mathrm{C}$ for 10 minutes, supernatant was discarded, $5 \mathrm{ml}$ of BHI broth was added to the sediment and incubated at $37^{\square} \mathrm{C}$ for $24 \mathrm{~h}$ (Cruickshank et al., 1975). For isolation of Streptococci, $0.9 \mathrm{ml}$ of Streptococci Selective Broth (SSB) was inoculated with $0.1 \mathrm{ml}$ of milk sample and incubated at room temperature in anaerobic jar for $24 \mathrm{~h}$. After incubation of milk samples in SSB, the broth was examined for the presence of Streptococcal organisms and further inoculated on to Edwards's medium. After incubation of milk samples in BHI broth the morphology of the organisms was studied with Gram's stain and cultural characters of the isolates was studied using different media such as Nutrient agar, Mac Conkey agar, Edward's medium, Eosin Methylene Blue agar (EMB), and Manitol Salt Agar (MSA). The isolates were also subjected to various biochemical tests as per the methods described by Cruickshank et al., (1975) and Bailey and Scott's (2007). Antibiogram was studied by using Antibiotic test discs manufactured by Hi-media Laboratories limited, Mumbai and Oxoid, UK with principle of disc diffusion method of Kirby and Baeur as described by Cruickshank et al., (1975). The antibiotics and their concentration used in the present study are Ampicillin $(10 \mu \mathrm{g})$, Ceftiofur $(30 \mu \mathrm{g})$, Ceftrioxone $(30 \mu \mathrm{g})$, Enrofloxacin $(30 \mu \mathrm{g})$ Gentamicin $(30 \mu \mathrm{g})$, Methicillin $(30 \mu \mathrm{g})$, and Tetracycline $(30 \mu \mathrm{g})$. The interpretations of test were carried out according to CLSI guidelines (2013).

\section{Results and Discussion}

A total of 1168 isolates were cultured from the milk samples, of which Staphylococcus $s p$. $(62.9 \%)$ was predominant followed by $E$. coli (24.4\%), Streptococcus sp. (8.3\%), and Pseudomonas sp. (4.4\%) (Fig. 1). The in-vitro antibiotic resistance pattern performed for the isolated organisms-Staphylococcus species, E. coli, Streptococcus sp and Pseudomonas sp. revealed that Staphylococci $s p$. showed highest percentage of resistance to methicillin $(82.5 \%)$ and least to ceftiofur $(40 \%)$. Most of the E.coli isolates were resistant to ampicillin $(61.5 \%)$ and minimum resistance was observed with ceftiofur (12\%). Streptococcus $s p$. isolates in the study showed maximum resistance to ceftrioxone $(60 \%)$ and minimum to ceftiofur (3\%). Pseudomonas isolates revealed maximum resistance to ampicillin $(58 \%)$ and minimum to ceftiofur $(29 \%)$.

The present study showed that Staphylococcus $s p$. was the predominant pathogen isolated followed by E. coli, Streptococcus sp. and Pseudomonas sp. For Staphylococcus isolates (735), among the drugs tested, ceftiofur was most sensitive showing $60 \%$ sensitivity, followed by tetracycline (42\%), gentamicin (37.5\%), enrofloxacin (34\%), ampicillin 
(18\%) and methicillin (17.5\%). The sensitivity pattern of Streptococcus isolates (97) showed highest sensitivity for ceftiofur (68\%), followed by enrofloxacin (50\%), gentamicin $(48 \%)$, tetaracycline (46\%), ampicillin (40\%), and ceftrioxone $(40 \%)$. E. coli isolates (284) showed highest sensitivity to ceftiofur (88\%) followed by enrofloxacin $(76 \%)$, ceftriaxone (75\%), tetracycline $(70 \%)$, gentamicin $(68 \%)$, and ampicillin (38\%). Pseudomonas isolates (52) showed highest sensitivity to ceftiofur (71\%) followed by ceftriaxone (69\%), gentamicin (58\%), tetracycline (52\%), enrofloxacin (50\%), and ampicillin (42\%) (Fig. 2). Alekish et al., (2013) studies showed that the most prevalent pathogens isolated were Staphylococcus aureus (53.4\%), E. coli (16\%), Streptococcus non-agalactiea (5.9\%), and coagulase negative Staphylococci (CNS) (5.9\%). The antibiotics for which, most of the isolated pathogens were sensitive to were enrofloxacin (61.2\%) and ciprofloxacin $(58.7 \%)$. While the ones that the pathogens were mostly resistant against were sulfa/trimethoprim (87.4\%), and penicillin (84.5\%). Samad Mosaferi et al., (2015) reported that the results of antibiotic susceptibility testing for samples isolated from mastitis in the dry period showed most sensitivity to enrofloxacin and tetracycline and least sensitivity to ampicillin and penicillin.
However, Sumathi et al., (2008) reported that gentamicin was the most effective drug for Staphylococcus, E. coli, Streptococcus and Klebsiella. While Jeykumar et al., (2012) reported that mastitis pathogens were highly resistant to penicillin $G$ and sensitive to enrofloxacin, Nadeem et al., 2013) reported that enrofloxacin was the effective drug followed by norfloxacin and gentamicin. Bhatt (2011) reported that Staphylococcus aureus and Pseudomonas evinced highest resistance to penicillin $\mathrm{G}$ and oxacillin antibiotics. The cause of differences among the results of the conducted studies might be due to indiscriminate and frequent use of antibiotics along with the variation in the type of drugs most commonly used in a particular area. The major reason that attribute to high sensitivity to Ceftiofur may be that they are not yet used in dairy cows and are relatively expensive. Their high cost and being not been used means these drugs have not been misused and hence are more effective compared to those that have been in use for quite a long time. The resistance of the isolates to the antibiotics including ceftiofur in the current study to some extent could also be due to biofilm formation by the pathogens tested (unpublished data) which could be reduced by the use of antibiofilm agents in combination with the antibiotics.

Fig.1 Prevalence of bacteria isolated from milk samples

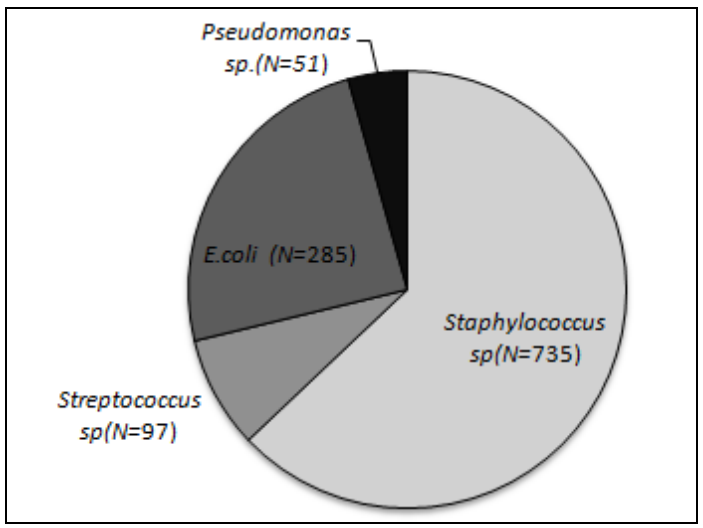

The profile showing prevalence of organisms the highest being Staphylococcus spp (62.9\%), followed by E. coli (24.4\%), Streptococci spp (8.3\%), and Pseudomonas spp (4.4\%). 
Fig.2 In-vitro Antimicrobial susceptibility test results of all milk bacterial isolates

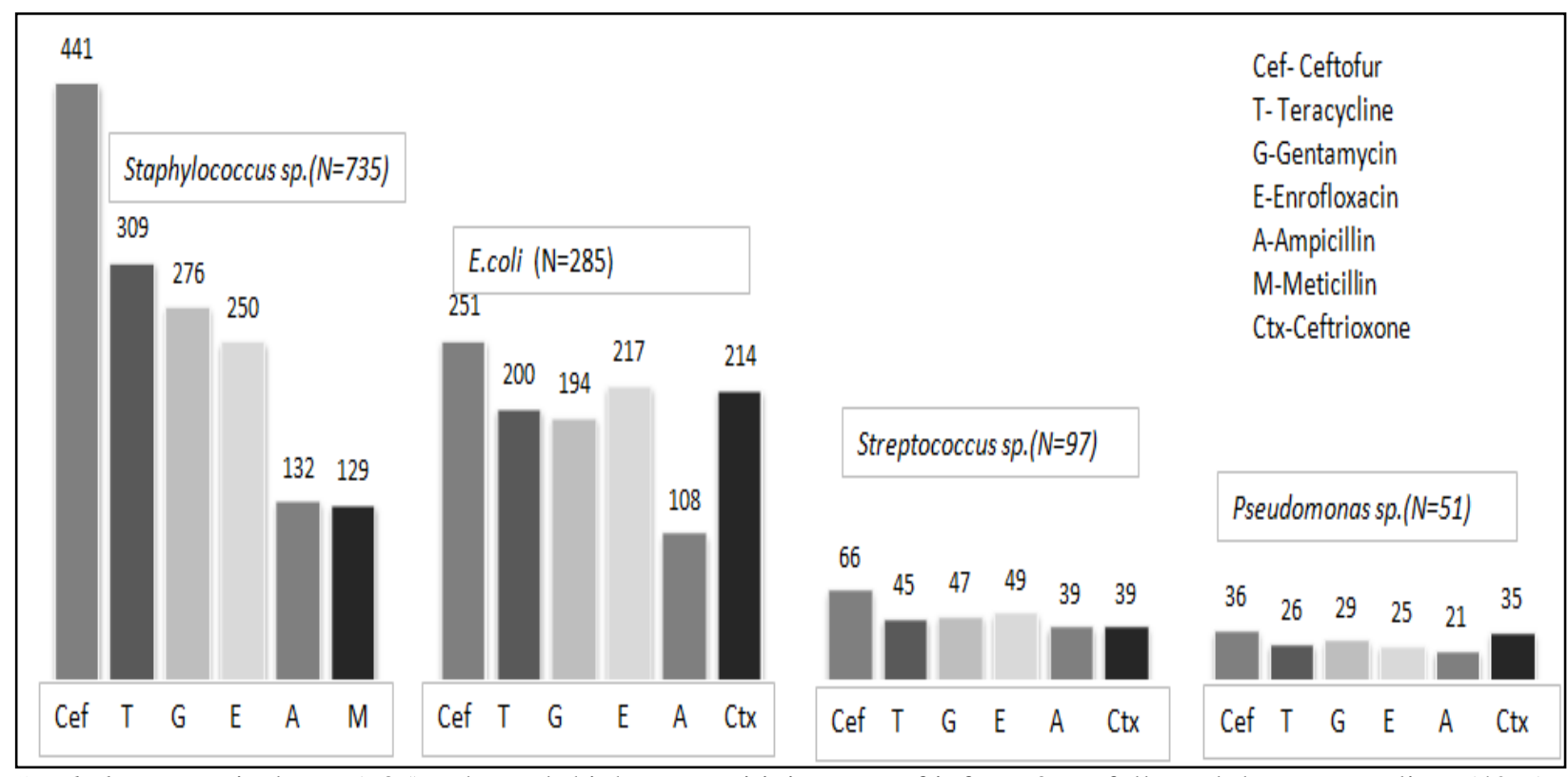

Staphylococcus isolates (735), showed highest sensitivity to ceftiofur $60 \%$, followed by tetracycline (42\%), gentamicin (37.5\%), enrofloxacin (34\%), ampicillin (18\%) and methicillin (17.5\%). E. coli isolates (284) showed highest sensitivity to ceftiofur $(88 \%)$ followed by enrofloxacin $(76 \%)$, ceftriaxone $(75 \%)$, tetracycline $(70 \%)$, gentamicin (68\%), and ampicillin (38\%). For Streptococcus isolates (97) showed highest sensitivity for ceftiofur (68\%), followed by enrofloxacin (50\%), gentamicin (48\%), tetaracycline (46\%), ampicillin (40\%), and ceftrioxone (40\%). Pseudomonas isolates (52) showed highest sensitivity to ceftiofur (71\%) followed by ceftriaxone (69\%), gentamicin (58\%), tetracycline (52\%), enrofloxacin (50\%), and ampicillin (42\%).

Regular screening of cultures for susceptibility pattern will be highly useful for selecting an appropriate antibiotic and also to know the changing trends of antibiotic resistance for developing antibiotic usage policy and for limiting the indiscriminate use of powerful antibiotics like cephalosporin as initial treatment.

In addition, awareness among farmers and clinicians for reducing the unnecessary use of antimicrobial drugs may restrict the development of multidrug resistance pattern.

As mastitis is a major cause of antibiotic use in dairy animals, early diagnosis, establishment of correct in-vitro antibiogram along with proper food and hygiene status of animal is very much essential to control mastitis and to prevent the spread of resistant clones of bacteria to other susceptible animals.

\section{Conflict of interest}

The authors declare that they have no competing interests.

\section{Acknowledgements}

We are thankful to all the farm owners who alerted us of and assisted us in the collection of milk samples. This work was supported by Zoetis, Mumbai, India, Department of Veterinary Microbiology and Department of Veterinary Biotechnology. College of Veterinary Science Rajendranagar Hyderabad.

\section{References}

Alekish M. O, Al-quda K M, Al-saleh A Prevalence of antimicrobial resistance among bacterial pathogens isolated from bovine mastitis in northern Jordan. Revue Méd. Vét., 2013, 164, 6, 319-326. 
Bailey and Scott's Diagnostic Microbiology 12th Edition Betty A. Forbes, Daniel F. Sahm, and Alice S. Weissfeld.

Bansal, B.K., Gupta, D.K. 2009. Economic analysis of bovine mastitis in India and PunjabA review. Indian J Dairy Sci. 67: 337-45.

Barkema, H.W., Deluyker, H.A., Schukken, Y.H. and Lam, T.J.G.M. 1999. Quartermilk somatic cell count at calving and at the first six milkings after calving. Prev. Vet. Med. 38: 1-9.

Bhatt, V.D, Patel, M.S., Joshi, C.G., Kunjadia, A. 2011. Identification and antibiogram of microbes associated with bovine mastitis. Anim Biotechnology. 22(3): 1639.

Blood, D.C. and Radostits, O.M. 1989. Veterinary Medicine: A Textbook of the Diseases of Cattle, Sheep, Pigs, Goats and Horses, 7th ed., 501.

Clinical and Laboratory Standards Institute Document M100-S23. Vol 33, No. 1. USA. Wayn PA. 2013. Performance standards for antimicrobial susceptibility testing: twenty first information supplement.

Cosgrove, S. E. \& Carmeli, Y. The impact of antimicrobial resistance on health and economic outcomes. Clin. Infect. Dis. 1433(36), 1433-7 (2014)

Cruickshank, R., Duguid, J.P., Marmion, B.P. and Swain, R.H.A. 1975. Medical Microbiology.12th edn. Vol. II, Churchill Livingstone, London.

Dhakal, I.P, Koshihara, T and Nagahata, H. 2007. Epidemiological and bacteriological survey of buffalo mastitis in Nepal. J.Vet. Med. Sci. 69; 1241-1245.

Jeykumar, M., Vinodkumar, G., Bimal, P., Bashir and Krovvid, S. 2013. Antibiogram of mastitis pathogens in the milk of crossbred cows in Namakkal district, Tamil Nadu. Vetworld.354-356.

Nadeem akram, Azhar h. Chaudhary, Shabbir ahmed, Manzoor a. Ghuman, Ghazala nawaz, Sajjad hussain. 2013. Isolation of bacteria from mastitis affected bovine milk and their antibiogram. European Journal of Veterinary Medicine, no. 1, $38-46$

Samad Mosaferi, Reza Ghabouli Mehrabani, Mansoor Khakpoor, Nader Ghabouli Mehrabani4, Amir Maleksabet, Faezeh. Prevalence of bacterial agents isolated from clinical cases of bovine mastitis in the dry period and the determination of their antibiotic sensitivity in Tabriz, Iran Hamidi. Journal of Coastal Life Medicine 2015; 3(9): 701-703

Sasidhar P V K, Ramana Reddy Y and Sudhakar rao G V 2002 Economics of mastitis, India Journal of Veterinary Science 72 (6): 439-440.

Seegers, H., Fourichon, C and Beaudeau, F. 2003. Production effects related to mastitis and mastitis economics in dairy cattle herds. Veterinary Research. 34: 475-491

Singh, K. B. and K. K. Baxi. 1982. Studies on the etiology in vitro sensitivity and treatment of subclinical mastitis in milch animals. Indian Veterinary Journal. 59:191-198.

Sumathi, B.R., Veeregowda, B.M. and Gomes, A.R. 2008. Prevalence and antimicrobial profile of bacterial isolates from clinical bovine mastitis. Vet. World. 1: 237-238.

Vinod Kumar. N, Sudheer Babu.G, Lahari. L, Radhika. B and Karthik. A. Antibiogram of Pathogens of Mastitis from Chittoor District: Andhra Pradesh. Indian Vet. J., August 2016, 93 (08): 66 - 68

\section{How to cite this article:}

Shiva Jyothi, Kalyani Putty, R.N. Ramani Pushpa, Hannan Umair, Amol, Vijay Muley, K. Dhanalakshmi and Narasimha Reddy, Y. 2018. Antibiogram of Bacterial Isolates Obtained from Milk Samples in and around Hyderabad, India. Int.J.Curr.Microbiol.App.Sci. 7(03): 3720-3724. doi: https://doi.org/10.20546/ijcmas.2018.703.430 